Alma Mater Studiorum - Università di Bologna DEPARTMENT OF ECONOMICS

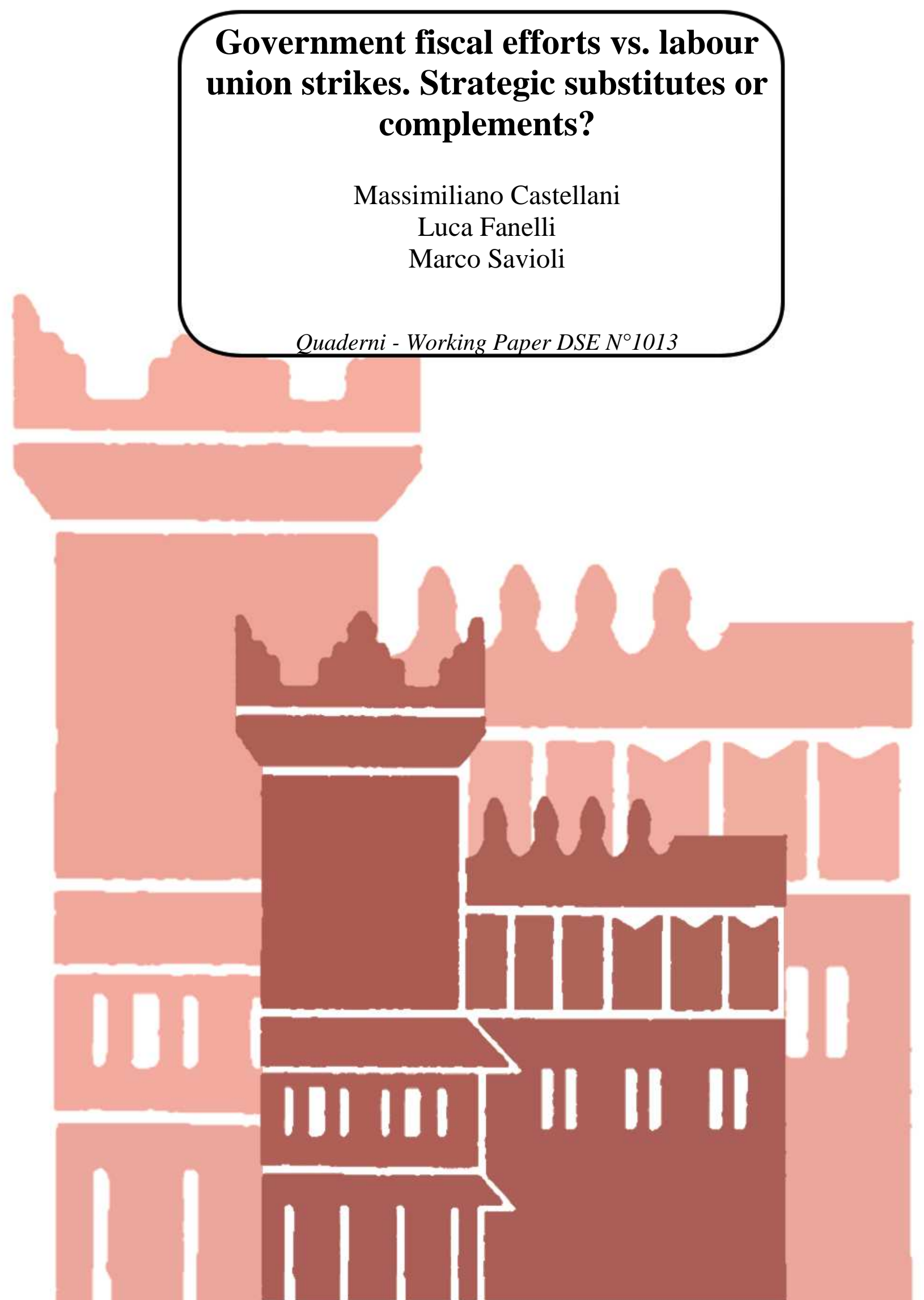




\title{
Government fiscal efforts vs. labour union strikes. Strategic substitutes or complements?
}

\author{
Massimiliano Castellani*, Luca Fanelli†, Marco Savioli ${ }^{\ddagger}$
}

\begin{abstract}
To unveil the strategic interaction between the government and the labour union in a unionised economy, a policy-game model is estimated by cointegrated Vector Autoregressive system using Italian quarterly data (1960-2009) on government budget surplus (fiscal efforts), hours not worked (strikes), unemployment and real wages. The long-run cointegration relationships are interpreted as the players' reaction functions and the long-run equilibrium as the equilibrium of the game. The identification of the long-run cointegration relationships allows indeed to determine if efforts and strikes are strategic complements or strategic substitutes. Finally, speed of long-run adjustment provides insights about the effectiveness of government and labour union strategies.
\end{abstract}

JEL classification: E62, J51, C72, C54, C32.

Keywords: Fiscal efforts, strikes, strategic substitutes, policy-game, speed of adjustment.

Acknowledgements: We are grateful to Pierpaolo Pattitoni for his helpful comments on an earlier version of this paper. We would also like to thank Karim Abadir, Guido Candela, Gabriele Fiorentini, Ragnar Nymoen, Gianluigi Pelloni, Thanasis Stengos, Fabio Zagonari and Lorenzo Zirulia, and all the participants to the RCEA Time Series Workshop 2013 and to the Department of Economics of the University of Bologna Seminars.

\footnotetext{
*Corresponding author. Department of Economics, University of Bologna, Italy. email: m.castellani@unibo.it

${ }^{\dagger}$ Department of Statistical Sciences and School of Economics, Management and Statistics, University of Bologna, Italy. email: luca.fanelli@unibo.it

${ }^{\ddagger}$ Department of Economics, University of Bologna, Italy; The Rimini Centre for Economic Analysis. email: m.savioli@unibo.it
} 


\section{Introduction}

In several OECD countries, especially in continental Europe, unions can influence the effects and the transmission mechanism of fiscal policies. Fiscal policies aim at mitigating unemployment, stimulating the economy and stabilising business cycles. The overall public budget (government budget surplus) denotes the fiscal efforts required to achieve government targets and maintain fiscal sustainability. ${ }^{1}$

Recently, Franzosi (2006) has argued that a government's partisanship and fiscal policy affect union behaviour and strikes: it takes two to tango. Governments use fiscal policies to gain the support of their electorate while unions use strikes to maximise support from workers. However, the government can not arbitrarily use fiscal policy to minimise unemployment (Kiander et al. 2004, Doménech \& García 2008) and maximise its support from the electorate and strikes are costly, therefore the strategic interaction between the government and the labour union is crucial to the effectiveness of fiscal efforts and strikes. ${ }^{2}$

The Italian economy is an ideal setting for investigating the economic and political interaction between governments and unions. Issues involving the interactions of fiscal policy and strikes are emblematic of Italian history and the post World War II configuration of Italian institutions. In Italy, the importance of labour unions both in industrial relationships and in economic and social policy issues is a well-known historical fact. Despite a decline in union density and the technological changes occurring in recent years, labour unions continue to play an important role in the performance of the labour market. ${ }^{3}$ In addition, since labour market institutions have not changed during recent years, labour unions can still affect the political and social climate. ${ }^{4}$ Italian industrial relationships have been marked by important political partici-

\footnotetext{
${ }^{1}$ Mierau et al. (2007), using a panel discrete choice model for 20 OECD countries for the period 1970-2003, found that fiscal adjustments are affected by economic and political variables (such as upcoming elections or broad policy reform). For advanced countries, Lavigne (2011) found that fiscal rules contribute to avoiding situations of fiscal distress. Heylen et al. (2013) found new evidence on the role of public sector efficiency for the success of fiscal consolidation.

${ }^{2}$ To capture the restrictiveness or expansiveness of fiscal policy, Schneider \& Zapal (2006) apply the growth accounting technique proposed by Von Hagen et al. (2002) and used by Hughes Hallett et al. (2003). They define net fiscal efforts as the part of the change in the budget not due to growth of the economy, a change in monetary policy conditions, or a change in the level of public debt.

${ }^{3}$ In the post-war period, the evolution of the Italian union density of employed workers displays a long cycle of about 30 years, with two peaks (about 50\%), one in 1950 and one in 1976. In 1960 and in 2009, the Italian union density was about $25 \%$ and $34 \%$, respectively. For more details, see Checchi \& Corneo (2000) and Franzosi (2006).

${ }^{4}$ The most important pro-labour legislative act, in Italy, was the Workers' charter of rights, enacted in 1970. The Italian constitutional law has increased work council powers and protects union activity. Notably, labour courts have extended the national wages agreement with unions, to cover all workers. Recently, the Workers'
} 
pation of the three biggest labour union confederations (CGIL, CISL and UIL) that cover almost all employees. Despite their ideological divisions, when the labour unions negotiated economic and social policy issues with the governments, their differences were vague and confederations often cooperated with each other. Italian labour unions and Leftist parties have historical similar political positions as both pursue the interests of workers. However, while labour unions have fought for higher wages, political parties have mainly sought to reduce unemployment rate.

In this paper, we explain how a government, mainly concerned with unemployment, and a labour union, mainly concerned with wages, may jointly determine the optimal level of their control variables: fiscal efforts and strikes. We start our analysis with a model in which we posit some restrictions to tackle parameter identification. By using Italian quarterly data (1960-2009) on government budget surplus (fiscal efforts), hours not worked (strikes), unemployment and real wages, we estimate a cointegrated Vector Autoregressive (VAR) model (Johansen 1995, Juselius 2006). In this framework, we interpret the long-term economic relationships as the players' reaction functions and the long-run equilibrium as the equilibrium of the game between the government and the labour union. The estimated model shows that fiscal efforts and strikes are indeed jointly determined and whether they are strategic substitutes or complements, in the long-run. ${ }^{5}$ Finally, we analyse the structure of adjustment towards equilibrium, using the concept of 'speed of long-run adjustment' introduced in Fanelli \& Paruolo (2010), to discern which player is more effective to reach its goal in the long-run equilibrium.

The remainder of the paper is organised as follows. In Section 2, we briefly review the relevant literature and emphasise our contribution. In Section 3, we introduce the model to identify the players' reaction functions. In Section 3.1, we use the vector error correction (VEC) methodology to empirically investigate the interaction between government and union. In Section 4, we propose an economic interpretation of our policy-game model and discuss its main implications. Section 5 concludes the paper.

\footnotetext{
charter of rights has been repeatedly reformed reducing the legal protection of workers.

${ }^{5}$ Following Bulow et al. (1985), players choices are called strategic complements if they mutually reinforce one another, and they are called strategic substitutes if they mutually offset one another. Games with strategic heterogeneity allow for both strategic substitutes and strategic complements (Monaco \& Sabarwal 2015).
} 


\section{Contribution to the literature}

The economic and political interaction of the strategies adopted by governments and unions is particularly important in understanding the economic and political performance of unionised economies, where a government's partisanship and fiscal policy greatly affect union behaviour and strikes. However, the interaction between fiscal policy and strikes is still a puzzle. With the notable exceptions of Ardagna (2007) and Gylfason \& Lindbeck (1986), most of the theoretical contributions analyse the impact of fiscal policy shocks in macroeconomic models with perfectly competitive labour markets and without considering strategic relationships between agents. However, both Ardagna (2007) and Gylfason \& Lindbeck (1986) do not consider strikes and do not estimate the strategic interaction between governments and unions.

Few studies do attempt to explain the puzzle of strikes through the lens of macroeconomic policy-game models where labour unions are powerful players. These macroeconomic policygame models are typically partial equilibrium models based on a sequential set of players' decisions, in which the union moves first and sets wages unilaterally, then the government selects public expenditure and, finally, firms make their hiring decisions (Azam \& Salmon 2004, Vernby 2007). Within this framework, workers may try to influence government policy through strikes. For instance, Azam \& Salmon (2004) apply an imperfect information framework in a policy-game between union and government where the government cannot credibly commit to a given level of employment-generating public expenditure and the union may use strikes to force the government to increase the same public expenditures. Following a similar approach, Vernby (2007) develops a policy-game where a union has the power to call strikes in order to entice the government to increase its job creation efforts. Contrary to Azam \& Salmon (2004), he focuses on how the incentive for the government to pursue an accommodationist policy depends on the type of electoral system. The studies of Azam \& Salmon (2004) and Vernby (2007), nevertheless, lack a symmetric game structure and no strategic interaction is explicitly considered in their econometric strategy.

Exploiting the definition of effort by Schneider \& Zapal (2006), our study contributes to the existing literature in several respects. First, using Italian quarterly data and the errorcorrection time series methodology, we estimate two long-run relationships between efforts, strikes, unemployment and real wages. In particular, the estimated model shows that fiscal 
efforts and strikes are jointly determined in the long-run and that efforts and strikes are strategic substitutes. Second, by combining our policy-game model with estimates of speed of long-run adjustment, we find the labour union as the more effective player. Third, to interpret those long-run relationships in a economic framework, we identify the 'deep' parameters of a game model that analyses the simultaneous strategic interaction between the government and the labour union.

\section{Empirical analysis}

In this section, we draw on Gylfason \& Lindbeck's (1986) game, in which government spending is determined within a macroeconomic framework involving endogenous utility-maximising government and labour union. Exploiting Franzosi's (2006) idea that a government's fiscal policy affect union behaviour and strikes, we propose a simultaneous policy-game in which the control variables of the government, $g$, and the labour union, $l$, are effort and strike. The stylized macroeconomic framework in which $g$ and $l$ play is also described by real wages, wage, and unemployment, un. We posit the policy-game equilibrium and the players' reaction functions are valid in the long-run. To estimate the long-run equilibrium and the long-run relationships, we identify the government's and the labour union's reaction function, effort ${ }^{R}$ and strike ${ }^{R}$, as a system of simultaneous cointegrated equations and specify effort ${ }^{R}$ and strike ${ }^{R}$ assuming that the government is directly affected by unemployment (Persson \& Tabellini 2000), and the labour union by real wages (Booth 1995). Given these exclusion restrictions, the interaction between the government and the labour union is captured by the system:

$$
\begin{gathered}
\text { effort }{ }^{R}+\beta_{g}^{0}+\beta_{g}^{u} \text { un }+\beta_{g}^{s} \text { strike }=0 \\
\text { strike }^{R}+\beta_{l}^{0}+\beta_{l}^{w} \text { wage }+\beta_{l}^{e} \text { effort }=0
\end{gathered}
$$

where $\beta_{i}^{j}$ represents the coefficient in the reaction function of the player $i=g, l$, for the variable $j=e, s, u, w$ (effort, strike, un, wage), and $\beta_{i}^{0}$ is the intercept of the player $i$ 's reaction function. ${ }^{6}$

In Subsection 3.1, we will focus on the case of Italy and test the hypothesis that the govern-

\footnotetext{
${ }^{6}$ The long-run equilibrium and the reaction functions (1) and (2) can be obtained as solution of a simple model of interaction between the government and the labour union, as done in Section 4. The reaction functions of our policy-game model have 'deep' parameters in line with the estimated parameters of functions (1) and (2).
} 
ment's and the labour union's reaction functions have negative or positive slopes $\left(\beta_{g}^{s}\right.$ and $\left.\beta_{l}^{e}\right)$, so that efforts and strikes are strategic substitutes or complements.

Assuming an interior solution exists, the equilibrium of the game is obtained from Eq. (1) and Eq. (2), i.e.

$$
\begin{aligned}
& \text { effort } *^{*}=\frac{\beta_{g}^{s} \beta_{l}^{0}-\beta_{g}^{0}}{1-\beta_{g}^{s} \beta_{l}^{e}}-\frac{\beta_{g}^{u}}{1-\beta_{g}^{s} \beta_{l}^{e}} \text { un }+\frac{\beta_{l}^{w} \beta_{g}^{s}}{1-\beta_{g}^{s} \beta_{l}^{e}} \text { wage } \\
& \text { strike }^{*}=\frac{\beta_{g}^{0} \beta_{l}^{e}-\beta_{l}^{0}}{1-\beta_{g}^{s} \beta_{l}^{e}}+\frac{\beta_{g}^{u} \beta_{l}^{e}}{1-\beta_{g}^{s} \beta_{l}^{e}} \text { un }-\frac{\beta_{l}^{w}}{1-\beta_{g}^{s} \beta_{l}^{e}} \text { wage }
\end{aligned}
$$

Defining effort $=\ln e$, un $=\ln u$, strike $=\ln s$ and wage $=\ln w$, the 'direct' equilibrium elasticity of $e$ and $s$ w.r.t. $u$ and $w$ are given by

$$
\begin{aligned}
& E_{e^{*}, u}=\frac{\partial e f f o r t^{*}}{\partial u n}=\frac{-\beta_{g}^{u}}{1-\beta_{g}^{s} \beta_{l}^{e}} \\
& E_{s^{*}, w}=\frac{\partial \text { strike }^{*}}{\partial \text { wage }}=\frac{-\beta_{l}^{w}}{1-\beta_{g}^{s} \beta_{l}^{e}}
\end{aligned}
$$

The 'indirect' equilibrium elasticity of efforts and strikes w.r.t. real wages and unemployment are

$$
\begin{aligned}
& E_{e^{*}, w}=\frac{\partial \text { effort }}{\partial w a g e}=\frac{\beta_{l}^{w} \beta_{g}^{s}}{1-\beta_{g}^{s} \beta_{l}^{e}} \\
& E_{s^{*}, u}=\frac{\partial \text { strike }}{\partial u n}=\frac{\beta_{g}^{u} \beta_{l}^{e}}{1-\beta_{g}^{s} \beta_{l}^{e}}
\end{aligned}
$$

The aforementioned equilibrium properties will be estimated in the next subsection and the policy-game model defined on the variables $e, s, u$ and $w$ will be presented in Section 4.

\subsection{The case of Italy}

Because of its history and institutional background, the Italian economy is well-suited to investigate the economic and political interaction of the strategies adopted by governments and unions. We base our empirical analysis on a hand-collected dataset comprising quarterly macroeconomic time series relative to the Italian economy. The data cover the period 1960.Q1-2009.Q4.

In particular, we consider quarterly observations of government budget surplus, hours not worked, unemployment and real wages, relative to the period 1960.Q1-2009.Q4, and proxy the variables of the model as follows (subscript $t$ denotes quarter): efforts are proxied by effort $_{t}=$ 
$\ln \left(1+\frac{S_{t}}{G D P_{t}}\right)$, where $S_{t}=-\Delta B_{t}$ is minus the public deficit, $B_{t}$ is the nominal stock of debt (source: Bank of Italy) and $G D P_{t}$ is the seasonally adjusted nominal Gross Domestic Product (source: OECD); strikes are proxied by strike $e_{t}=\ln \left(1+\frac{H_{t}}{P O P_{t}}\right)$, where $H_{t}$ is the amount of hours not worked due to labour disputes arising from the labour contract (source: Italian National Institute of Statistics) and $P O P_{t}$ is the active population aged 15-64 (source: OECD); unemployment is proxied by $u n_{t}=\ln \left(1+\frac{U_{t}}{L F_{t}}\right)$, where $U_{t}$ are the unemployed workers, $L F_{t}$ is the labour force and $\frac{U_{t}}{L F_{t}}$ is the seasonally adjusted unemployment rate (source: OECD); real wages are proxied by wage $_{t}=\frac{W_{t}}{P_{t}}$, where $W_{t}$ is the hourly wage index of the manufacturing sector and $P_{t}$ is the Harmonised Index of Consumer Prices (source: Italian National Institute of Statistics). From the definitions above, it turns out that effort $t_{t}$ can be interpreted as a measure of the budget surplus the government obtains, over the level of GDP, while strike $e_{t}$ is a measure of the amount of hours not worked per capita. ${ }^{7}$ Some descriptive statistics are presented in Table 1. The time series of main interest, effort $t_{t}$ and strike $_{t}$, are plotted in Figure 1.

Table 1: Descriptive statistics

\begin{tabular}{ccccc}
\hline \hline Variable & Mean & Std. Dev. & Min & Max \\
\hline effort & -0.077 & 0.056 & -0.214 & 0.031 \\
strike & 0.305 & 0.321 & 0.007 & 1.751 \\
un & 0.068 & 0.025 & 0.026 & 0.108 \\
wage & 0.806 & 0.247 & 0.293 & 1.057 \\
\hline \multicolumn{5}{c}{ Number of observations: 200}
\end{tabular}

The four variables of our model are collected in the vector $X_{t}=\left(\text { effort }_{t}, \text { strike }_{t}, \text { un }_{t}, \text { wage }_{t}\right)^{\prime}$ and modelled as a VAR system with four lags, a constant and three deterministic seasonal dummies. In principle, many episodes and institutional changes might have impacted the variables included in $X_{t}$, hence we could potentially enrich our VAR specification with a relatively large set of intervention (impulse/step) dummies in $D_{t}$ associated with several historical episodes. ${ }^{8}$ How-

\footnotetext{
${ }^{7}$ There are various definitions and several measures of strikes. Hamann et al. (2012), following Hyman (1989) and Walsh (1983), defined 'general strike' (or 'protest strike') as a temporary, national stoppage of work by workers from many industries, directed against the executive or legislative arms of government, to enforce a demand or give voice to a grievance. Using this definition, they distinguished and collected data on political and economic strikes for 16 Western European countries between 1980 and 2006. Lindvall (2013), on the basis of theories of organizational power resources, explains why political strikes are rare in countries with strong union movements. According to his reckoning, between 1980 and 2008, there were only 10 political strikes in Italy.

${ }^{8}$ For instance, on March 13, 1979, Italy entered in the European Monetary System and signed an agreement for the maintenance of a fixed exchange parity w.r.t. the ECU; on February 12, 1981, the separation of the Treasury from the Central Bank occurred; on November 1, 1993, the Treaty on European Union came into force in Italy, bringing to the creation of the European Central Bank and the European System of Central Banks on the January 1,1999 .
} 

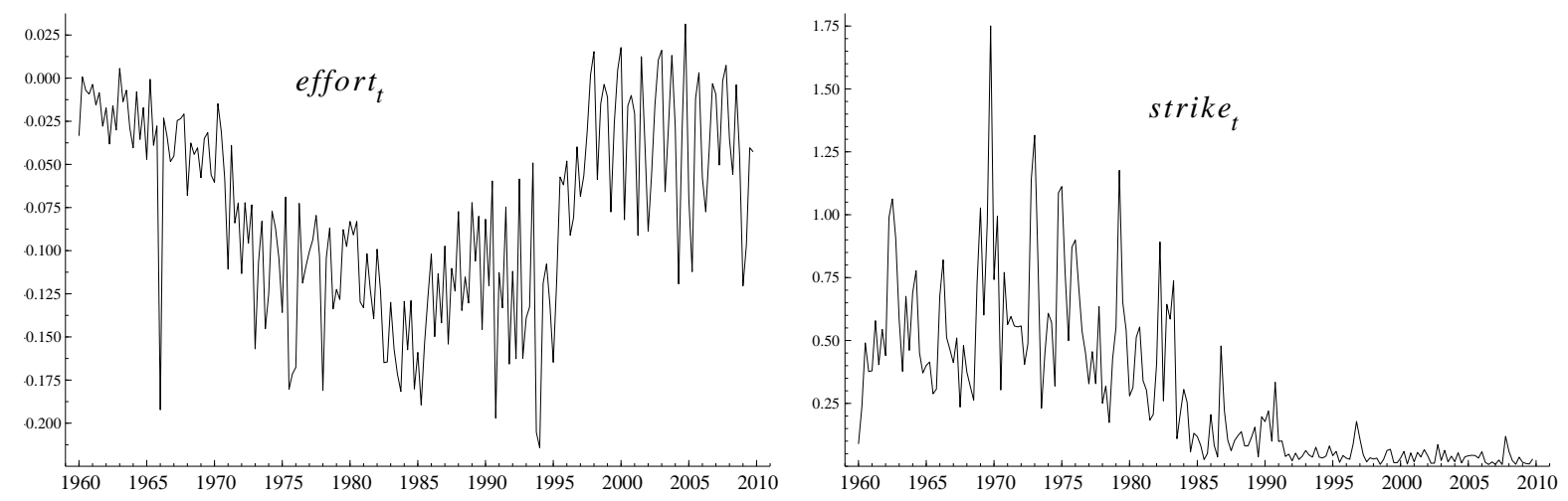

Figure 1: effort $t_{t}$ and strike $_{t}$ over the period 1960.Q1-2009.Q4

ever, our preliminary analyses showed that the VAR-model results on the long-run equilibrium we discuss below are substantially invariant to the inclusion of many intervention dummies. ${ }^{9}$ The reference VAR model is therefore given by

$$
X_{t}=\sum_{i=1}^{4} A_{i} X_{t-i}+\mu+\Phi D_{t}+\varepsilon_{t} \quad t=1, \ldots, T
$$

where $A_{i}$ is a $4 \times A$ matrix of parameters, $i=1,2,3,4, \mu$ is a $4 \times 1$ vector of constants, $D_{t}$ is a $3 \times 1$ vector containing three centered deterministic seasonal dummies with associated coefficients in the $4 \times 3$ matrix $\Phi$, and $\varepsilon_{t}$ is a 4 -dimensional white noise process with covariance matrix $\Sigma_{\varepsilon}$.

The upper panel of Table 2 reports some residuals diagnostic tests at the system level on the VAR in Eq. (9) estimated on the period 1960.Q1-2009.Q4 $(T=196$, excluding the four initial lags). The diagnostic checks suggest that, even though the VAR disturbances are not Gaussian, the residuals obtained from the estimated system with four lags are consistent with the occurrence of serially uncorrelated disturbances.

We also computed standard information criteria and some residuals diagnostic tests at the single-equation level. Results are reported in the lower panel of Table 2, where we consider VAR systems with 1 up to 5 lags. The first three columns of Table 2 reports the Akaike information criterion $(A I C)$, the Hannan-Quinn information criterion $(H Q)$ and the Schwartz information criterion $(S C)$. The last two columns sketch the Lagrange multiplier vector test for the null of

\footnotetext{
${ }^{9}$ Among the many robustness checks we performed, we took also into account the government's ideology (left vs. right), the electoral system (majoritarian vs. proportional system), the election date, and union membership. Since these political variables do not result significant, the variables considered in our model represent the relevant political-economic environment (Castañeda 1995). We also estimated the system with nominal wages and inflation instead of real wages without finding significant differences for the other variables. Results are available upon request from the authors.
} 
Table 2: Diagnostic tests on the estimated VAR system in Eq. (9)

\begin{tabular}{lcccc}
\hline \hline Equations: & effort $_{t}$ & strike $_{t}$ & un $_{t}$ & wage $_{t}$ \\
\hline LM-AR 1-5 test: & 1.60 & 0.80 & 2.41 & 2.03 \\
& {$[0.16]$} & {$[0.55]$} & {$[0.04]$} & {$[0.08]$} \\
LM-Normality test: & 17.88 & 54.44 & 8.23 & 38.86 \\
& {$[0.00]$} & {$[0.00]$} & {$[0.02]$} & {$[0.00]$}
\end{tabular}

\begin{tabular}{cccccc}
\hline lags & $A I C$ & $H Q$ & $S C$ & LM-AR 1-5 & LM-Normality \\
\hline 1 & -19.7105 & -19.5746 & $-19.3748^{*}$ & 2.58 & 137.44 \\
& & & & {$[0.00]$} & {$[0.00]$} \\
2 & -19.6634 & -19.4187 & -19.0591 & 2.37 & 130.51 \\
& & & & {$[0.00]$} & {$[0.00]$} \\
3 & -19.7177 & -19.3644 & -18.8449 & 2.12 & 122.53 \\
& & & {$[0.00]$} & {$[0.00]$} \\
4 & $-20.1487^{*}$ & $-19.6866^{*}$ & -19.0073 & 1.27 & 118.99 \\
& & & {$[0.07]$} & {$[0.00]$} \\
5 & -20.0790 & -19.5082 & -18.6691 & 1.44 & 93.71 \\
& & & & {$[0.01]$} & {$[0.00]$} \\
\hline
\end{tabular}

The estimation sample is 1960.Q1-2009.Q4, including initial lags. P-values are reported in squared brackets.

UPPER PANEL: LM-AR 1-5 is a Lagrange multiplier test for the null of absence of autocorrelation up to lag order 5. LM-Normality is a Lagrange multiplier test for the null of Gaussian distribution.

LOWER PANEL: $A I C$ is the Akaike information criterion; $H Q$ is the Hannan-Quinn information criterion; $S C$ is the Schwartz information criterion. LM-AR 1-5 is a Lagrange multiplier vector test for the null of absence of autocorrelation in the VAR disturbances up to lag order 5. LM-Normality is a Lagrange multiplier vector test for the null of Gaussian distribution.

uncorrelated VAR disturbances against the alternative of correlation up to 5 lags (LM-AR 1-5) and the Lagrange multiplier vector test for the null of Gaussian disturbances (LM-Normality), respectively. ${ }^{10}$ The Akaike and Hannan-Quinn criteria select 4 lags, while the Schwartz criterion selects 1 lag. The LM-AR 1-5 test suggests that only in the VAR with 4 lags the disturbances are serially uncorrelated at the $5 \%$ level of significance.

Summing up the evidence in Table 1, we conduct our empirical investigations with the VAR above with four lags. Mild deviations from normality can not be considered a major obstacle to the empirical investigations we conduct in this paper, see Gonzalo (1994).

\subsection{Long-run equilibrium}

When the VAR system (9) is driven by unit roots and the variables are cointegrated, it is useful to consider its VEC counterpart (Johansen 1995):

$$
\Delta X_{t}=\alpha\left(\beta^{\prime}, \mu_{c}\right)\left(\begin{array}{c}
X_{t-1} \\
1
\end{array}\right)+\sum_{j=1}^{3} \Gamma_{i} \Delta X_{t-i}+\mu_{u}+\Phi D_{t}+\varepsilon_{t} \quad t=1, \ldots, T
$$

\footnotetext{
${ }^{10}$ See e.g. Hendry (1995) for details about the information criteria and diagnostic tests.
} 
where $\Delta X_{t}=X_{t}-X_{t-1}, \Gamma_{j}$ are $4 \times 4$ matrices which depend on the original VAR parameters and $\alpha$ and $\beta$ are matrices of dimension $4 \times r$ of full column rank $r<4$. Under a set of suitable identifying restrictions on $\beta$ of the type $\beta=\beta_{I}$, the $r$-dimensional vector $\beta_{I}^{\prime} X_{t-1}$ captures the long-run relationships embedded in the system, while the coefficients in the matrix $\alpha$ capture the short-run (next-period) adjustment of the variables in $\Delta X_{t}$ to the equilibrium.

Table 3: LR trace cointegration rank test

\begin{tabular}{cccc}
\hline \hline$H_{0}: r \leq j$ & Trace & asym. p-value & iid-boot. p-value \\
\hline$j=0$ & 76.902 & 0.000 & 0.000 \\
$j=1$ & 43.289 & 0.001 & 0.005 \\
$j=2$ & 17.065 & 0.027 & 0.072 \\
$j=3$ & 6.507 & 0.011 & 0.030 \\
\hline
\end{tabular}

The estimation sample is 1960.Q1-2009.Q4, including initial lags. The cointegration rank test is conducted in the context of the VAR system in Eq. (9) considering the case of unrestricted constant $\mu$. 'asym. p-value' denotes p-values computed from the asymptotic approximation of the test and 'iid-boot. p-value' denotes p-values computed using the iid bootstrap procedure discussed in Cavaliere et al. (2012).

In Table 3 we summarise the results of the LR Trace test (Johansen 1995) to determine the cointegration rank, $r$. The test is carried out by considering an unrestricted specification for the constant, and treating the system as integrated at most of order one (I(1)). In addition to reporting the p-values associated with the sequential LR Trace test using the asymptotic critical values, we also compute the non-parametric iid-bootstrap counterpart of the p-values, discussed in Cavaliere et al. (2012). When the tendency to over-reject the test in finite samples is corrected with the bootstrap, $r=2$ cointegrating relationships are accepted at the $5 \%$ level of significance. We further observe that with $r=3$, it would be difficult to identify another relationship other than the two predicted by our policy-game model. With $r=2$, the quantity $\beta^{\prime} X_{t-1}$ in Eq. (10) is a 2-dimensional vector and the parameters in $\beta$ need to be identified, i.e. $\beta$ must fulfil the restriction $\beta=\beta_{I}$, where $\beta_{I}$ matches the conditions discussed in Johansen (1995). In addition, $\mu_{c}=\left(\beta_{g}^{0}, \beta_{l}^{0}\right)^{\prime}$ is the portion of the constant we force to enter the cointegration relationships.

The first column of the matrix $\beta_{I}, \beta_{I, 1}$, identifies the beta coefficients of the long-run government's reaction function, i.e. the quantity $v_{e, t-1}=\beta_{I, 1}^{\prime} X_{t-1}+\beta_{g}^{0}=$ effort $_{t-1}+\beta_{g}^{0}+$ $\beta_{g}^{u} u n_{t-1}+\beta_{g}^{s}$ strike $_{t-1}$ captures the deviation of the observed efforts, effort $t_{t-1}$, from its longrun equilibrium level, effort ${ }^{R}$, as implied by Eq. (1). The second column of the matrix $\beta_{I}, \beta_{I, 2}$, identifies the beta coefficients of the long-run labour union's reaction function, i.e. 
$v_{s, t-1}=\beta_{I, 2}^{\prime} X_{t-1}+\beta_{l}^{0}=$ strike $_{t-1}+\beta_{l}^{0}+\beta_{l}^{w}$ wage $_{t-1}+\beta_{l}^{e}$ effort $_{t-1}$ captures the deviation of the observed strikes, strike $t_{-1}$, from its long-run equilibrium level, strike ${ }^{R}$, as implied by Eq. (2). Overall, the simultaneous system of cointegrated equations is given by

$$
\left(\beta_{I}^{\prime}, \mu_{c}\right)\left(\begin{array}{c}
X_{t-1} \\
1
\end{array}\right)=v_{t-1}
$$

where $v_{t-1}=\left(v_{e, t-1}, v_{s, t-1}\right)^{\prime}$. This system is exactly identified, but we also consider a set of joint restrictions on the not significant adjustment coefficients $\alpha$ of the control variables effort $t_{t}$ and strike. . In particular, we found that effort is 'weakly exogenous' w.r.t. the identified $\beta_{I}$ (Hendry 1995), meaning that there is no next-period adjustment of $\Delta$ effort $_{t}$ to the two long-run equilibrium relationships. Thus, considering the set of restrictions on $\beta_{I}$ and $\alpha$ jointly, we have 2 over-identifying (testable) restrictions.

The estimated identified long-run relationships are given by

$$
\begin{aligned}
& \left(\hat{\beta}_{I}^{\prime}, \hat{\mu}_{c}\right)\left(\begin{array}{c}
X_{t-1} \\
1
\end{array}\right)=\left\{\begin{array}{l}
\hat{\beta}_{I, 1}^{\prime} X_{t-1}+\hat{\beta}_{g}^{0} \\
\hat{\beta}_{I, 2}^{\prime} X_{t-1}+\hat{\beta}_{l}^{0}
\end{array}\right. \\
& =\left\{\begin{array}{c}
\text { effort }_{t-1}+\underset{(0.089)}{0.245 \text { strike }_{t-1}}+\underset{(0.937)}{4.901 \text { un }_{t-1}-0.493} \\
\text { strike }_{t-1}+\underset{(0.652)}{1.214 \text { effort }_{t-1}}+\underset{(0.126)}{0.664 \text { wage }_{t-1}-0.836}
\end{array}\right.
\end{aligned}
$$

and are also reported in Table 4, along with the adjustment coefficients $\alpha$. The estimation of $\alpha$ and $\beta_{I}$ was carried out by ML. The LR test reported in the bottom part of Table 4 can be regarded as a statistical test for the overall specification. ${ }^{11}$

The sign of the beta coefficients of efforts and strikes in $\hat{\beta}_{I}$ show that the government and the labour union have strategic substitutes, meaning that a more 'aggressive' player decreases the level of the variable controlled by the other player. The estimated beta coefficients allow us to compute the game model's elasticities derived in Eq.s (5)-(6) and summarised in Table 5. At equilibrium, the 'direct' elasticities are negative and the 'indirect' elasticities are positive: an

\footnotetext{
${ }^{11}$ It is worth to explicit our orthogonality assumption through which other players have been marginalised out from the model. Although the proxy we have used for strikes is a measure of 'general strikes', the results in Table 4 suggest that the possible effects of the strikes directed against other players are conveyed in the cointegration residual, $\hat{v}_{s, t-1}=$ strike $_{t-1}+\hat{\beta}_{l}^{0}+\hat{\beta}_{l}^{w}$ wage $_{t-1}+\hat{\beta}_{l}^{e}$ effort $t_{t-1}$, which captures the transitory part of strike $e_{t}$ not explained by our model. It follows that the long-run properties of the time series we have used for strike are well captured by our policy-game model.
} 
Table 4: Estimated cointegration relationships and adjustment coefficients for fixed cointegration $\operatorname{rank} r=2$

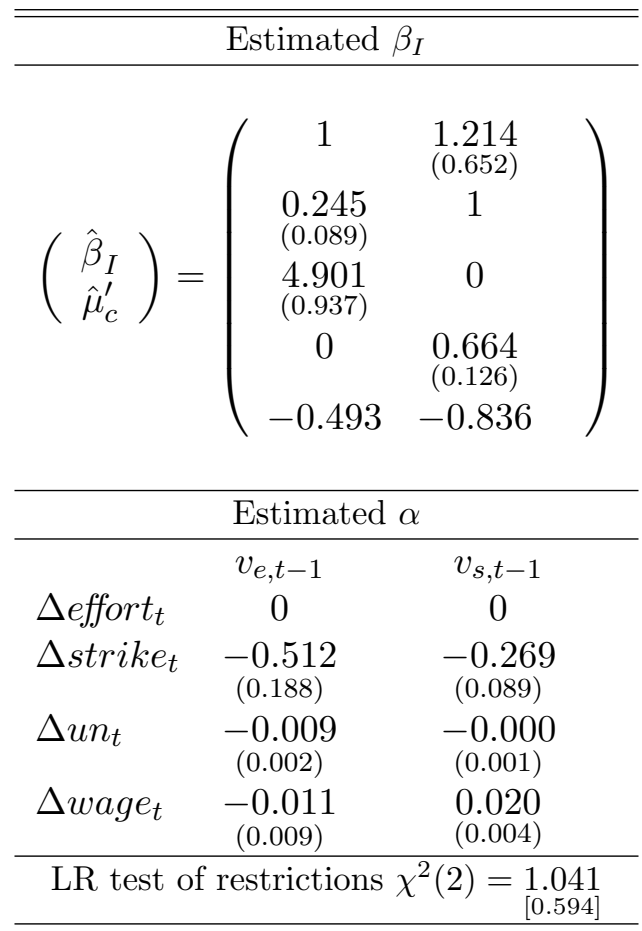

The estimation sample is 1960.Q1-2009.Q4, including initial lags.

UPPER PANEL: estimated cointegration relationships.

LOWER PANEL: estimated adjustment coefficients. The LR test is a likelihood ratio test for the zero restrictions in the $\alpha$ matrix. Standard errors in parentheses; p-values in squared brackets.

increase in the variables directly (indirectly) affecting the players reduce (expand) their optimal strategy. Regarding the magnitude of the elasticities, we note that the labour union is more reactive than the government $(8.469>6.976,0.945>0.232)$, and that changes in unemployment have stronger effects than changes in wages $(6.976>0.232,8.469>0.945)$, at the long-run equilibrium. The estimated strikes elasticities testify as the decrease in unemployment and the increase in real wages seem to explain the historical long-run decrease in strikes in Italy. Furthtermore, since the Maastricht Treaty and the Stability and Growth Pact effectiveness imply a higher government' efforts for Italy, our model predicts that this equilibrium's sustainability depends on both a decrease in unemployment and an increase in real wages. With such trends in unemployment and real wages, the predicted effect on the level of strikes is negative. 
Table 5: Nash equilibrium properties

\begin{tabular}{c}
\hline \hline ML estimates of the elasticities in Eq.s (5)-(6) \\
\hline$\hat{E}_{e^{*}, u}=\frac{-\hat{\beta}_{g}^{u}}{1-\hat{\beta}_{g}^{s} \hat{\beta}_{l}^{e}}=-6.976$ \\
$\hat{E}_{s^{*}, w}=\frac{-\hat{\beta}_{l}^{w}}{1-\hat{\beta}_{g}^{s} \hat{\beta}_{l}^{e}}=-0.945$ \\
\hline$\hat{E}_{e^{*}, w}=\frac{\hat{\beta}_{l}^{d} \hat{\beta}_{g}^{s}}{1-\hat{\beta}_{g}^{s} \hat{\beta}_{l}^{e}}=0.232$ \\
$\hat{E}_{s^{*}, u}=\frac{\hat{\beta}_{g}^{u} \hat{\beta}_{l}^{e}}{1-\hat{\beta}_{g}^{s} \hat{\beta}_{l}^{e}}=8.469$ \\
\hline
\end{tabular}

The estimation sample is 1960.Q1-2009.Q4, including initial lags. Standard errors in parentheses.

\subsection{Speed of adjustment}

The parameters in the matrix $\alpha$ of the VEC in Eq. (10) are short-run adjustment coefficients and capture the next-period (next-quarter in our case) responses of the variables in $\Delta X_{t}$ to lagged disequilibria $v_{t-1}$ (i.e. to lagged deviations of efforts and strikes from their cointegration levels).

The estimated $\alpha$ s reported in the lower panel of Table 4 suggest that the government does not adjust in the short-run to any of the identified long-run relationships, while the labour union adjusts significantly to the error correction terms associated with the two estimated reaction functions. More precisely, there is no error-correction mechanism at work in the $\Delta$ effort $t_{t^{-}}$ equation, meaning that effort $t_{t}$ is 'weakly exogenous' w.r.t. the identified $\beta_{I}$. These results indicate, with some qualifications, that effort $t_{t}$ acts as a sort of stochastic (common) trend driving the sub-system formed by effort $t_{t}$ and strike $_{t}$, while the labour union acts as the 'buffer' in the adjustment process, in the sense that strike $e_{t}$ is the variable which corrects, quarterby-quarter, the path of adjustment such that deviations from the two cointegrating reaction functions do not drift too far apart. It turns out that the labour union's strikes policy is influenced by the government's efforts not only in the long-run, as suggested by Eq. (2) and its estimated counterpart in Eq. (12), but over shorter horizons as well.

In order to fully understand the nature of the adjustment process towards equilibrium implied by our estimated model, it is necessary to disentangle the concepts of 'short-run' and and 'long-run' adjustment. The short-run adjustment depends on the elements of the matrix $\alpha$, while the long-run adjustment depends on all parameters $\alpha, \Gamma_{1}, \Gamma_{2}$ and $\Gamma_{3}$. Following Fanelli \& Paruolo (2010), we define the speed of long-run adjustment of effort $t_{t}\left(\right.$ strike $\left._{t}\right)$ to a unit per- 
turbation in $\hat{v}_{e, t-1}\left(\hat{v}_{s, t-1}\right)$, as the number of quarters employed by effort (strike $\left._{t}\right)$ to complete a portion $\lambda(0<\lambda<1)$ of the adjustment path towards its long-run position; the 'long-run position' is the long-run impact of $\hat{v}_{e, t-1}\left(\hat{v}_{s, t-1}\right)$ on effort ${ }_{t}\left(\right.$ strike $\left._{t}\right)$, i.e. the long-run -or totalmultiplier. Obviously, if there is no significant long-run impact of $\hat{v}_{e, t-1}\left(\hat{v}_{s, t-1}\right)$ on effort $t_{t}$ $\left(\right.$ strike $\left._{t}\right)$, it does not make sense to measure the speed of adjustment.

Table 6: Estimated speed of long-run adjustment (quarters) with $90 \%$ confidence intervals

\begin{tabular}{lccc}
\hline \hline & Speed of adjustment of & effort $_{t}$ & strike $_{t}$ \\
\hline to perturbation to $\hat{\beta}_{I, 1}^{\prime} X_{t-1}+\hat{\beta}_{g}^{0}=\hat{v}_{e, t-1}$ & no adj. & no adj. \\
to perturbation to $\hat{\beta}_{I, 2}^{\prime} X_{t-1}+\hat{\beta}_{l}^{0}=\hat{v}_{s, t-1}$ & no adj. & 2 \\
\end{tabular}

The estimation sample is 1960.Q1-2009.Q4, including initial lags. $\hat{v}_{e, t-1}$ and $\hat{v}_{s, t-1}$ are defined in Eq. (11) of the paper. The reported measures of speed of long-run adjustment correspond to the long-run $\lambda$-lives (obtained with $\lambda=0.5$ ) introduced in Fanelli \& Paruolo (2010). 90\% confidence intervals in parentheses are computed by a non-parametric bootstrap procedure based on $M=100$ replications.

Table 6 shows the estimated speeds of the long-run adjustment stemming from our VEC system, obtained with $\lambda=0.5$ (half-life), along with $90 \%$ confidence intervals. We compute not only the speed of long-run adjustment of effort ${ }_{t}\left(\right.$ strike $\left._{t}\right)$ to a perturbation in $\hat{v}_{e, t-1}\left(\hat{v}_{s, t-1}\right)$, but also speeds of 'cross-long-run adjustment', i.e. the speeds of long-run adjustment of effort $t_{t}$ $\left(\right.$ strike $\left._{t}\right)$ to perturbations in $\hat{v}_{s, t-1}\left(\hat{v}_{e, t-1}\right)$. The only significant result is the speed of long-run adjustment of strike to $\hat{v}_{s, t-1}$, which is given by 2 quarters (point estimate) and can reach up to a maximum of 42 quarters according to the upper bound of its $90 \%$ confidence set.

This result confirms the estimated $\alpha \mathrm{s}$ in Table 4 . Since strike $_{t}$ is the variable which adjusts both in the short-run and in the long-run to the equilibrium, we can assert that the labour union is the more effective player. Strikes policy is 'actively' used to reach the labour union's goals and the long-run equilibrium of the system. On the contrary, the government's efforts adjust to strikes only in the long-run.

\section{Game model}

In this section, we develop a policy-game model in which the long-run equilibrium and the reaction functions (1) and (2) can be obtained as solutions of a simple model of interaction between two players: the government and the labour union. To simplify the political issues of the game we model the government and the labour union as unitary players, hence we do not 
discuss their politics. In particular, policy makers and union leaders implement the optimal policy of the median voter without any agency problem between policy makers and electors, and between union leaders and workers, respectively. ${ }^{12}$

We assume that both players' objective functions are separable into the part involving the government and the labour union's interaction on efforts, strikes, unemployment and real wages, and the part involving other players (e.g. the organisation of employers or Central Bank) or other variables (e.g. the inflation rate or interest rate). ${ }^{13}$ Using this orthogonality assumption, we focus on the 'deep' parameters of players' objective functions and, as well as in the estimated reaction functions, we assume that the players' objective functions are defined on the government' efforts, $e$, the labour union' strikes, $s$, unemployment, $u$ and real wages, $w$. In particular, the effect of $w$ on the government's objective function, $G$, and the effect of $u$ on the labour union's objective function, $L$, are only indirect: $G(e ; s(w), u)$ and $L(s ; e(u), w)$. Consistent with a wage bargaining approach, we assume that the effect of $w$ on $L$ is positive. However, since strikes are costly for all agents participating in industrial relationships (Hicks 1932), $w$ enters $L$ also as opportunity cost of strikes.

When the government and the labour union interact, the government focuses its efforts on maximising support from its electorate which depends on the unemployment rate, the fundamental variable on which society evaluates macroeconomic outcomes (Persson \& Tabellini 2000). Thus, the government's objective function, $G$, depends, for any level of labour union' strikes and unemployment, on its efforts $e$. In particular, $G$ is specified in the form

$$
G=v u^{-\tau} s^{-\sigma_{g}} e-e^{1+\eta_{g}}
$$

The first part of Eq. (13) captures the positive effect (benefit) of efforts. Since the parameters $-\tau$ and $-\sigma_{g}$ are negative, unemployment and strikes diminish the benefit of efforts. The parameter $\eta_{g}>0$ in the second part of Eq. (13) measures the cost of efforts. Finally, $v>0$

\footnotetext{
${ }^{12} \mathrm{By}$ this assumption, we can aggregate heterogeneous individual preferences into a unique government and union's objective function (Booth 1984).

${ }^{13}$ In principle, the organisation of employers does affect government and labour union, but we maintain that this effect is only marginal in the interplay between government and labour union, in line with our partial equilibrium approach. In the 1970s and 1980s several authors investigated the interaction between monetary policy and wage setting in terms of policy-games. Gylfason \& Lindbeck (1994) analysed first the non-neutrality of money through a policy-game between the central bank and the labour union. More recently, Acocella \& Di Bartolomeo (2004) studied non-neutrality in policy-games involving one or more trade unions.
} 
is a parameter measuring the cost-benefit ratio of efforts. Observe that electors have higher probability of being unemployed with a higher $u$ and a higher $s$ generates a loss to the economy, so we assume electors perceive a lower value for government' efforts $e$ whenever $u$ and $s$ increase.

The derivative of $G$ w.r.t. the control variable of the player $g$ is given by

$$
G_{e}=v u^{-\tau} s^{-\sigma_{g}}-\left(1+\eta_{g}\right) e^{\eta_{g}}
$$

where the term $v u^{-\tau} s^{-\sigma_{g}}$ is the constant marginal benefit of $e$ and $\left(1+\eta_{g}\right) e^{\eta_{g}}$ is the increasing marginal cost of $e$. Note that, to capture the idea of a trade-off between costs and benefits of the government's efforts, $G_{e}$ has an inverted-U shape, that is the government's control variable $e$ has a positive and then a negative effect on $G$ :

$$
G_{e=0}=v u^{-\tau} s^{-\sigma_{g}}>0 \quad G_{e \rightarrow+\infty}=-\infty<0
$$

In the strategic interaction between the government and the labour union, the labour union uses strikes to maximise support from workers who are mainly influenced by real wages (Booth 1995). Therefore, for any given government efforts and wages, the labour union's objective function depends on strikes $s$. Specifically, the objective function $L$ is specified in the form

$$
L=r w^{-\rho} e^{-\eta_{l}} s-s^{1+\sigma_{l}}+a w
$$

The first addend of Eq. (16) captures the positive effect (benefit) of strikes because they are intended as effective ways of participation in the socio-economic political process. ${ }^{14}$ Since the parameters $-\rho$ and $-\eta_{l}$ are negative, real wages and efforts decrease the benefit of strikes. The parameter $\sigma_{l}>0$ in the second addend of Eq. (16) measures the cost of strikes. The parameter $a$ in the third addend of Eq. (16) is assumed to be high enough so that the derivative of $L$ w.r.t. $w$ is positive. Finally, $r>0$ is a parameter measuring the cost-benefit ratio of strikes. Starting from the idea that union leaders are motivated by personal advancement (Ross 1953) and that their support from workers increases when the union calls strikes against undisciplined government, we assume that the positive effect of $s$ decreases in efforts.

\footnotetext{
${ }^{14}$ Lee \& Roemer (2005) studied a policy-game model where trade unions interact with endogenously formed partisan political parties to explain changing political preferences for and against the unionised labour market regime.
} 
The derivative of $L$ w.r.t. the control variable of the player $l$ is given by

$$
L_{s}=r w^{-\rho} e^{-\eta_{l}}-\left(1+\sigma_{l}\right) s^{\sigma_{l}}
$$

where the term $r w^{-\rho} e^{-\eta_{l}}$ captures the constant marginal benefit of $s$ and $\left(1+\sigma_{l}\right) s^{\sigma_{l}}$ is the increasing marginal cost of $s$. By analogy with the government trade-off between costs and benefits, $L_{s}$ has an inverted-U shape, that is the labour union's control variable $s$ has a positive and then a negative effect on $L$ :

$$
L_{s=0}=r w^{-\rho} e^{-\eta_{l}}>0 \quad L_{s \rightarrow+\infty}=-\infty<0
$$

Given the strategic interaction between the two players, the optimal strategies arise from their reaction functions. The government's reaction function is obtained by maximising its objective function. From the First Order Condition of this problem (by imposing $G_{e}=0$ in Eq. (14)), we obtain the government's reaction function that we express in natural logs:

$$
\ln e^{R}=\frac{1}{\eta_{g}} \ln \left(\frac{v}{1+\eta_{g}}\right)-\frac{\tau}{\eta_{g}} \ln u-\frac{\sigma_{g}}{\eta_{g}} \ln s
$$

Since the government exhibits strategic substitutes, a more 'aggressive' labour union lowers the marginal benefit of the government' efforts, see Eq. (13). Therefore, the government's reaction function has a negative slope: $-\frac{\sigma_{g}}{\eta_{g}}<0$. Eq. (1) corresponds to Eq. (19), where effort $=\ln e$, un $=\ln u$, strike $=\ln s, \beta_{g}^{0}=\frac{-1}{\eta_{g}} \ln \left(\frac{v}{1+\eta_{g}}\right), \beta_{g}^{u}=\frac{\tau}{\eta_{g}}>0$ and $\beta_{g}^{s}=\frac{\sigma_{g}}{\eta_{g}}>0$.

The labour union's reaction function is calculated by maximising its objective function. By imposing $L_{s}=0$ in Eq. (17) and taking natural logs, we obtain the labour union's reaction function:

$$
\ln s^{R}=\frac{1}{\sigma_{l}} \ln \left(\frac{r}{1+\sigma_{l}}\right)-\frac{\rho}{\sigma_{l}} \ln w-\frac{\eta_{l}}{\sigma_{l}} \ln e
$$

Since the labour union exhibits strategic substitutes, a more aggressive government lowers the marginal benefit of strikes, see Eq. (16). The labour union's reaction function has a negative slope: $-\frac{\eta_{l}}{\sigma_{l}}<0$. As above, Eq. (2) corresponds to Eq. (20), where wage $=\ln w$, $\beta_{l}^{0}=\frac{-1}{\sigma_{l}} \ln \left(\frac{r}{1+\sigma_{l}}\right), \beta_{l}^{w}=\frac{\rho}{\sigma_{l}}>0$ and $\beta_{l}^{e}=-\frac{\eta_{l}}{\sigma_{l}}<0$. 
By (19) and (20), we obtain the Nash equilibrium of the game:

$$
\begin{aligned}
\ln e^{*}= & \frac{\sigma_{l}}{\eta_{g} \sigma_{l}-\eta_{l} \sigma_{g}}\left[\ln \left(\frac{v}{1+\eta_{g}}\right)-\tau \ln u\right]+ \\
& +\frac{-\sigma_{g}}{\eta_{g} \sigma_{l}-\eta_{l} \sigma_{g}}\left[\ln \left(\frac{r}{1+\sigma_{l}}\right)-\rho \ln w\right] \\
\ln s^{*}= & \frac{-\eta_{l}}{\eta_{g} \sigma_{l}-\eta_{l} \sigma_{g}}\left[\ln \left(\frac{v}{1+\eta_{g}}\right)-\tau \ln u\right]+ \\
& +\frac{\eta_{g}}{\eta_{g} \sigma_{l}-\eta_{l} \sigma_{g}}\left[\ln \left(\frac{r}{1+\sigma_{l}}\right)-\rho \ln w\right]
\end{aligned}
$$

which correspond to Eq.s (3) and (4).

\section{Conclusions}

In this paper, we model the strategic interaction between governments and labour unions in unionised economies. Our contribution focuses on strikes, government budget surplus, unemployment and real wages interdependencies. It helps to explain how government's fiscal policy and labour unions' strikes policy are implemented in the long-run.

Using time series methods, we show that the proposed policy-game model is based on sound empirical support. At equilibrium, changes in unemployment have stronger effects than changes in wages. The effect of unemployment on efforts and strikes is respectively negative and positive, while the effect of real wages on efforts and strikes is respectively positive and negative. Since the Maastricht Treaty and the Stability and Growth Pact effectiveness imply a higher government' efforts for Italy, our model predicts that this equilibrium's sustainability depends on both a decrease in unemployment and an increase in real wages. With such trends in unemployment and real wages, the predicted effect on the level of strikes is negative.

This evidence suggests that in Italy the government and the labour union have been both powerful economic players, each capable of affecting the choice of the other player. The estimated coefficients of the long-run players' reaction functions show that the government and the labour union exhibit strategic substitutes. In addition, the estimated structure of adjustment to equilibrium reveals that the labour union uses strikes policy more effectively than the government uses fiscal policy. 


\section{References}

Acocella, N. \& Di Bartolomeo, G. (2004), 'Non-neutrality of monetary policy in policy games', European Journal of Political Economy 20(3), 695-707.

Ardagna, S. (2007), 'Fiscal policy in unionized labor markets', Journal of Economic Dynamics and Control 31(5), 1498-1534.

Azam, J. P. \& Salmon, C. (2004), 'Strikes and political activism of trade unions: Theory and application to Bangladesh', Public Choice 119(3), 311-334.

Booth, A. (1984), 'A public choice model of trade union behaviour and membership', The Economic Journal 94(376), 883-898.

Booth, A. L. (1995), The economics of the trade union, Cambridge University Press.

Bulow, J. I., Geanakoplos, J. D. \& Klemperer, P. D. (1985), 'Multimarket oligopoly: Strategic substitutes and complements', The Journal of Political Economy pp. 488-511.

Castañeda, G. (1995), 'The political economy of Mexico, 1940-1988: A game theoretical view', European Journal of Political Economy 11(2), 291-316.

Cavaliere, G., Rahbek, A. \& Taylor, A. M. (2012), 'Bootstrap determination of the co-integration rank in vector autoregressive models', Econometrica 80(4), 1721-1740.

Checchi, D. \& Corneo, G. (2000), 'Trade union membership: theories and evidence for Italy', Lavoro e relazioni industriali 2.

Doménech, R. \& García, J. R. (2008), 'Unemployment, taxation and public expenditure in OECD economies', European Journal of Political Economy 24(1), 202-217.

Fanelli, L. \& Paruolo, P. (2010), 'Speed of adjustment in cointegrated systems', Journal of Econometrics 158(1), 130-141.

Franzosi, R. (2006), The puzzle of strikes: class and state strategies in postwar Italy, Cambridge University Press.

Gonzalo, J. (1994), 'Five alternative methods of estimating long-run equilibrium relationships', Journal of Econometrics 60(1), 203-233.

Gylfason, T. \& Lindbeck, A. (1986), 'Endogenous unions and governments: A game-theoretic approach', European Economic Review 30(1), 5-26.

Gylfason, T. \& Lindbeck, A. (1994), 'The interaction of monetary policy and wages', Public Choice 79(1), 33-46.

Hamann, K., Johnston, A. \& Kelly, J. (2012), 'Unions against governments explaining general strikes in Western Europe, 1980-2006', Comparative Political Studies .

Hendry, D. F. (1995), Dynamic econometrics, OUP Oxford.

Heylen, F., Hoebeeck, A. \& Buyse, T. (2013), 'Government efficiency, institutions, and the effects of fiscal consolidation on public debt', European Journal of Political Economy .

Hicks, J. R. (1932), The theory of wages, P. Smith. 
Hughes Hallett, A., von Hagen, J. \& Lewis, J. (2003), Fiscal Policy in Europe 1999-2003: An Evidence Based Analysis, Centre for Economic Policy Research.

Hyman, R. (1989), Strikes, Macmillan Press.

Johansen, S. (1995), Likelihood-based inference in cointegrated vector autoregressive models, OUP Oxford.

Juselius, K. (2006), The cointegrated VAR model: methodology and applications: methodology and applications, OUP Oxford.

Kiander, J., Kilponen, J. \& Vilmunen, J. (2004), 'Labor taxation, public finance, and wage determination: evidence from OECD countries', European Journal of Political Economy 20(4), 983-999.

Lavigne, R. (2011), 'The political and institutional determinants of fiscal adjustment: Entering and exiting fiscal distress', European Journal of Political Economy 27(1), 17-35.

Lee, W. \& Roemer, J. E. (2005), 'The rise and fall of unionised labour markets: a political economy approach', The Economic Journal 115(500), 28-67.

Lindvall, J. (2013), 'Union density and political strikes', World Politics 65(3), 539-569.

Mierau, J. O., Jong-A-Pin, R. \& De Haan, J. (2007), 'Do political variables affect fiscal policy adjustment decisions? New empirical evidence', Public Choice 133(3-4), 297-319.

Monaco, A. J. \& Sabarwal, T. (2015), 'Games with strategic complements and substitutes', Economic Theory pp. 1-27.

Persson, T. \& Tabellini, G. (2000), Political economics: explaining economic policy, The MIT press.

Ross, A. M. (1953), Trade union wage policy, Univ of California Press.

Schneider, O. \& Zapal, J. (2006), 'Fiscal policy in new EU member states: go East, prudent man!', Post-Communist Economies 18(2), 139-166.

Vernby, K. (2007), 'Strikes are more common in countries with majoritarian electoral systems', Public Choice 132(1), 65-84.

Von Hagen, J., Hughes Hallett, A. \& Strauch, R. (2002), 'Budgetary consolidation in Europe: quality, economic conditions, and persistence', Journal of the Japanese and International Economies 16(4), 512-535.

Walsh, K. (1983), Strikes in Europe and the United States: measurement and incidence, Francis Pinter Pub. 


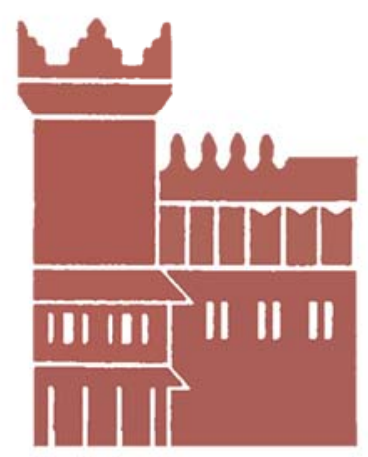

Alma Mater Studiorum - Università di Bologna DEPARTMENT OF ECONOMICS

Strada Maggiore 45

40125 Bologna - Italy

Tel. +39051 2092604

Fax +390512092664

http://www.dse.unibo.it 